\title{
Technological Indicators of Direct Dumping Zone as a Part of Combined Mining Method
}

\author{
Andrey Sysoev 1,*, Elena Zlobina ${ }^{1}$, Igor Katanov ${ }^{1}$, and Jurgen Kretschmann ${ }^{2}$ \\ ${ }^{1}$ T.F. Gorbachev Kuzbass State Technical University, Open pit Mining Department, 650000, \\ Kemerovo, Russian Federation \\ ${ }^{2}$ Technische Hochschule Georg Agricola (THGA), Bochum, Germany
}

\begin{abstract}
Under the conditions of a combined mining system overburden is developed using a transport and non-transport technologies, specific costs for non-transport technology are lower than transport costs. The change in the non-transport bench height led to the redistribution of the volumes of transport and non-transport overburden. With an increase in the volume of non-transport overburden, the share of more expensive transport overburden is decreases, while the technical and economic indicators of the non-transport zone deteriorate due to an increase in re-excavation volumes. The change in the non-transport bench height affects the recasting ratio and the annual advance coal face line, which determine the cost of developing the overburden. This article presents the results of a study of the laws of change in the recasting ratio and the annual advance coal face line, depending on the non-transport bench height within a combined mining system of flat seam. The obtained patterns were established as a result of solving problems of substantiating typical excavation schemes of the direct dumping method and developing a mathematical model for identifying excavation schemes with the subsequent calculation of their technological indicators.
\end{abstract}

\section{Introduction}

The use of walking dragline excavators in open cast mining horizontal and gentle seams of mineral in certain mining conditions allows to reduce development costs [1-4] by compared with other types of single-bucket excavators, and also give the possibility of using the developed space for internal dumps [5-8], which increases the environmental friendliness of production.

With a mixed system of mining flat seams, which provides for a combination of transport method and direct dumping method the work requires the establishment of a rational ratio of relevant volumes of stripping work that would ensure cost minimization. Decision this task is relevant, in particular, when mining flat seams of the Leninsky and Yerunakovsky geological economic regions of the central Kuzbass [9-11].

The non-transport bench height is a control technological parameter. Establishing its rational value is a necessary condition for the effectiveness of a mixed mining system.

\footnotetext{
*Corresponding author: ia sys@mail.ru
} 
Analysis of excavation schemes flat seam under combined system of mining shows that there is no general methodological approach to choosing the non-transport bench height. Therefore, the available tools for numerical modeling of the direct dumping method do not include the solution of this problem.

To study the patterns of changes in the main technological indicators of the nontransport zone depending on the non-transport bench height under combined mining system, it is necessary to justify the structure of the excavation schemes allow you to calculate the performance of direct dumping method in a wide range of values non-transport bench height [12-15].

\section{Results and Discussion}

\subsection{The graphic model mining benches by direct dumping method}

The mathematical model of the parameters and indicators of excavation schemes is based on a logical mechanism for identifying the structure of the scheme depending on the given non-transport bench height (figure 1).

The general principle of identification of excavation schemes is a comparison of the volume of stripping cut, taking into degree of fragmentation, with the maximum internal dump capacity.

\section{Dump side}

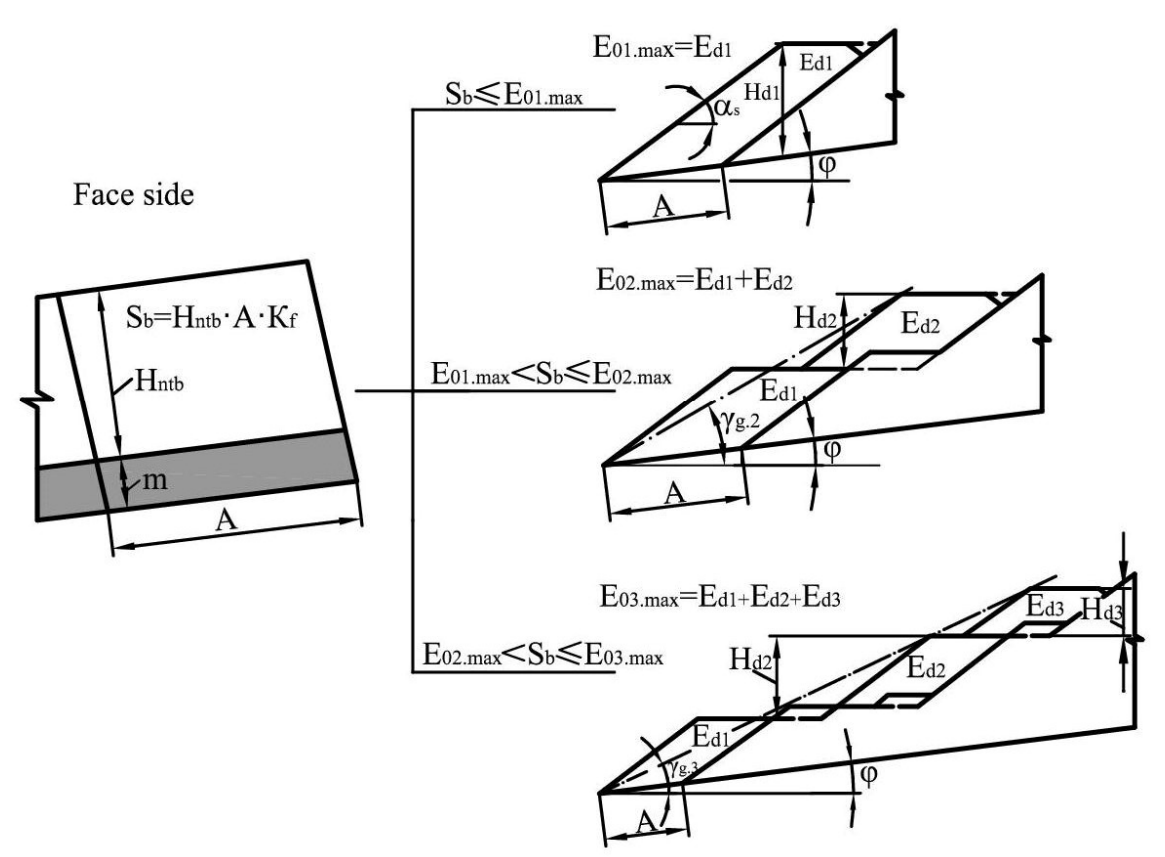

Fig. 1. The structure graphic model mining benches by direct dumping method.

In model the following legends are accepted: $S_{\mathrm{b}}-$ stripping cut section, $\mathrm{m}^{2} ; E_{\mathrm{oi} \text { max }}-$ maximum internal dump capacity based on operating parameters and slope stability, $\mathrm{m}^{2} ; i-$ number of tiers of the internal dump; $E_{\mathrm{d} 1}, E_{\mathrm{d} 2}, E_{\mathrm{d} 3}-$ internal dump capacity; $\gamma_{\mathrm{g} . \mathrm{i}}-$ general 
angle internal dump; $K_{\mathrm{f}}-$ degree of fragmentation; $H_{\mathrm{ntb}}-$ non-transport bench height, $\mathrm{m} ; A$ - excavator bench, $\mathrm{m} ; \varphi$ - amount of inclination; $m$ - seam thickness, $\mathrm{m}$.

The internal dump capacity base on factors: digging and dumping reach of walking dragline; pivot axis position dragline, amount of inclination, general angle internal dump and excavator bench. Identification of excavation schemes links internal dump capacity and technological parameters.

\subsection{The typical structures of excavation schemes flat seam mining}

Based on the generalization of the characteristics of groups of excavation schemes of nontransport bench (height 15-50 m, flat seam) their typical structures are systematized for tier dump which reflects the relationship of the volume of stripping cut with the internal dump capacity (figure 2).

The structure of the excavation scheme depends on the non-transport bench height, amount of inclination, seam thickness, digging and dumping reach of walking dragline. The greater the non-transport bench height, the greater the number of tiers of the internal dump, therefore, the structure and organization of work according to the scheme of excavation is more complicated.

The technological schemes apply the principle of «Raychikhinskaya» excavation scheme. The peculiarity of the scheme is the general horizontal level of the highway alignment of the dragline and the top of the first tier dump. This ensures sufficient controllability of a walking excavator with a dragline and a high average level of the dragline for the overburden.

a)

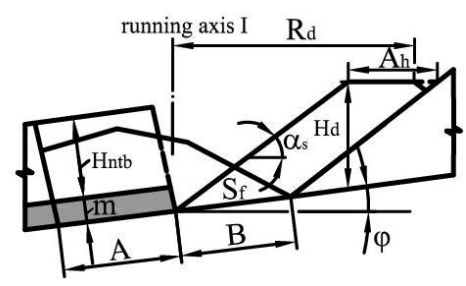

b)

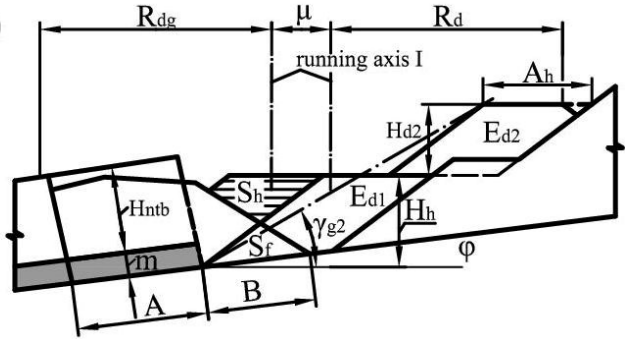

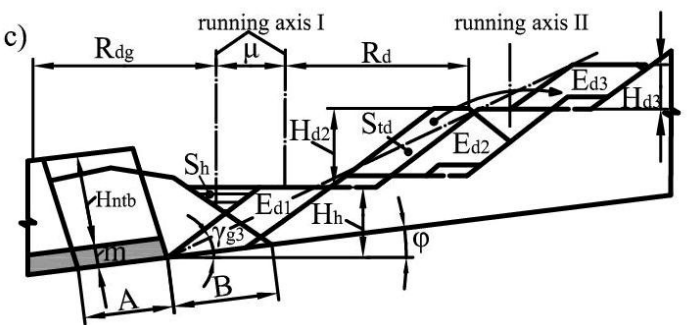

Fig.2. The dragline's excavation schemes flat seam mining: $\mathrm{a}$ - one-tier dump; $\mathrm{b}$ - two-tier dump; $\mathrm{c}-$ three-tier dump.

The following legends are accepted: $H_{\mathrm{ntb}}-$ non-transport bench height, m; $m$ - seam thickness, m; $\varphi$ - amount of inclination; $A$ - excavator bench, $\mathrm{m} ; B$ - burden, $\mathrm{m} ; R_{\mathrm{dg}}-$ digging reach, $\mathrm{m} ; R_{\mathrm{d}}-$ dumping reach, $\mathrm{m} ; E_{\mathrm{d} . \mathrm{i}}-$ internal dump capacity, $\mathrm{m}^{2} ; H_{\mathrm{d} . \mathrm{i}}-$ dump slope height, $\mathrm{m} ; i$-number of tiers of the internal dump; $H_{\mathrm{h}}$ - highway alignment height, $\mathrm{m} ; S_{\mathrm{h}}$ - highway alignment section, $\mathrm{m}^{2} ; S_{\mathrm{td}}-$ temporary dump section, $\mathrm{m}^{2 ;} \mu$ - running axis horizontal displacement, $\mathrm{m} ; A_{\mathrm{h}}-$ horizontal alignment excavator bench, $\mathrm{m}$. 


\subsection{Technological parameters of the non-transport zone}

To determine the qualitative and quantitative patterns of influence of the non-transport bench height, as a controlling factor on the technological indicators of the combined mining system, calculations were performed in a wide range of initial data typical of coal deposits of the central Kuzbass: amount of inclination is from 0 to 9 degrees, seam thickness from 4 to $12 \mathrm{~m}$, dragline boom length from 50 to $100 \mathrm{~m}$, bucket capacity from 5 to $40 \mathrm{~m}^{3}$, nontransport bench height from 15 to $50 \mathrm{~m}$, quarry face from 300 to $1500 \mathrm{~m}$. The total number of examined were more than 400 variants. A fragment of the calculations is presented in the table.

The enlarged technological indicators of the non-transport zone at the combined mining system of flat seams are the total recasting ratio and annual advance coal face line. These indicators depend on the parameters of the mining-and-geological conditions (seam thickness and amount of inclination), walking draglines specifications (boom length and bucket capacity), and non-transport bench height.

Table. The technological performance excavation schemes (ESh 10.70, $\varphi=8^{\circ}$ )

\begin{tabular}{|c|c|c|c|c|c|c|c|c|}
\hline $\begin{array}{c}\boldsymbol{H}_{\text {ntb, }} \\
\mathbf{m}\end{array}$ & $\begin{array}{c}\boldsymbol{C}_{\mathbf{s h}} \\
\mathbf{m}^{\mathbf{3}} / \mathbf{s h}\end{array}$ & $\begin{array}{c}\boldsymbol{C}_{\mathbf{y r}}, \\
\text { thou. } \mathbf{~ m}^{\mathbf{3}} / \mathbf{y r}\end{array}$ & $\boldsymbol{K}_{\text {throw }}$ & $\begin{array}{c}\boldsymbol{T}_{\mathbf{d g}}, \\
\mathbf{s h}\end{array}$ & $\begin{array}{c}\boldsymbol{V}_{\mathbf{y r . f}}, \\
\mathbf{m} / \mathbf{y r}\end{array}$ & $\boldsymbol{K}_{\mathbf{r e}}$ & $\begin{array}{c}\boldsymbol{V}_{\text {yr.nt, }} \\
\text { thou. }^{\mathbf{3}}\end{array}$ & $\begin{array}{c}\boldsymbol{V}_{\text {yr.t, }} \\
\text { thou. } \mathbf{m}^{\mathbf{3}}\end{array}$ \\
\hline 15 & 2520 & 1852 & 0.150 & 140 & 183 & 0.176 & 2664 & 10063 \\
\hline 20 & 2506 & 1842 & 0.170 & 184 & 139 & 0.188 & 2652 & 7003 \\
\hline 25 & 1655 & 1217 & 0.190 & 343 & 74.9 & 0.249 & 1752 & 3406 \\
\hline 30 & 1737 & 1276 & 0.195 & 392 & 65.6 & 0.286 & 1838 & 2650 \\
\hline 35 & 1384 & 1018 & 0.182 & 606 & 42.4 & 0.630 & 1415 & 1491 \\
\hline 40 & 1592 & 1170 & 0.176 & 659 & 39.0 & 0.792 & 1507 & 1160 \\
\hline
\end{tabular}

$H_{\mathrm{ntb}}-$ non-transport bench height, $\mathrm{m} ; C_{\mathrm{sh}}-$ average output per shift of dragline, $\mathrm{m}^{3} / \mathrm{sh} ; C_{\mathrm{yr}}$ average annual output of dragline, thou. $\mathrm{m}^{3} / \mathrm{yr} ; K_{\text {throw }}$ - throw ratio; $T_{\mathrm{dg}}-$ digging time, sh; $V_{\mathrm{yr}, \mathrm{f}}$ - annual advance coal face line, $\mathrm{m} / \mathrm{yr} ; K_{\mathrm{re}}-$ total recasting ratio; $V_{\mathrm{yr} . n t}-$ annual volume non-transport zone, thou. $\mathrm{m}^{3} ; V_{\mathrm{yr} . t}-$ annual volume transport zone, thou. $\mathrm{m}^{3}$.

\subsection{The total recasting ratio}

Increasing non-transport bench height leads to increase of recasting ratio for all groups excavation schemes, which is associated with an increase in the number of stages of rock rehandling, and the increasing complexity of the technological interconnection between them.

Multivariate grapho-analytical calculations show, that for all models of walking dragline excavators, the dependence of recasting ratio on the non-transport bench height is not continuous. The structural breaks in this functional dependence occur during the transition from one-tier excavation schemes to two-tier excavation schemes, as well as during the transition from two-tier excavation schemes to three-tier excavation schemes.

If in the first case the jump of the recasting ratio is less than $5 \%$ of the overburden, then in the second case the recasting ratio more than doubled (figure 3). 


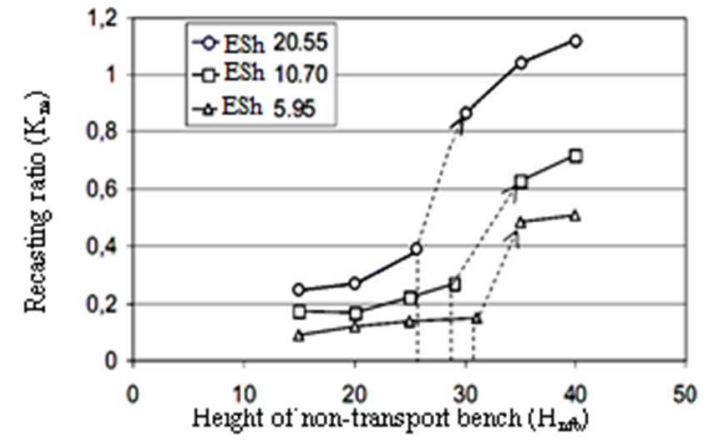

Fig. 3. Dependence of recasting ratio on of non-transport bench height.

\subsection{The non-transport bench height}

The maximum non-transport bench height, corresponding to the full capacity of the twotier internal dump taking technological parameters dragline and slope stability internal dump, determines the boundary of the transition to the three-tier excavation schemes.

Based on processing the results of calculations of technological parameters of the excavation schemes for various models of walking dragline and different mining-and-geological conditions parameters, built in AutoCAD, a functional connection was established between the maximum non-transport bench height (equal to the two-tier internal dump capacity $\left.\left(H_{\text {ntb.d2 }}, \mathrm{m}\right)\right)$ with the amount of inclination and excavator boom length $\left(L_{\mathrm{b}}, \mathrm{m}\right)$ :

$$
H_{\text {ntb.d2 }}=(0.73-0.02 \varphi) L_{\mathrm{b}}-0.002 L_{\mathrm{b}}^{2} \text {. }
$$

\subsection{Annual advance coal face line}

Annual advance coal face line is a technological indicator that determines the performance of the excavation scheme for mineral resources. Obviously, annual advance coal face line is proportional to the bucket capacity and inversely proportional to the overburden amount dragging by the dragline, which is characterized by the value $\left(1+K_{\mathrm{re}}\right)$. In figure 4 shows the interrelation between the quantities $\left(V_{\mathrm{f}} / E\right)$ and $\left(1+K_{\mathrm{re}}\right)$ based on the results of graphanalytical calculations.

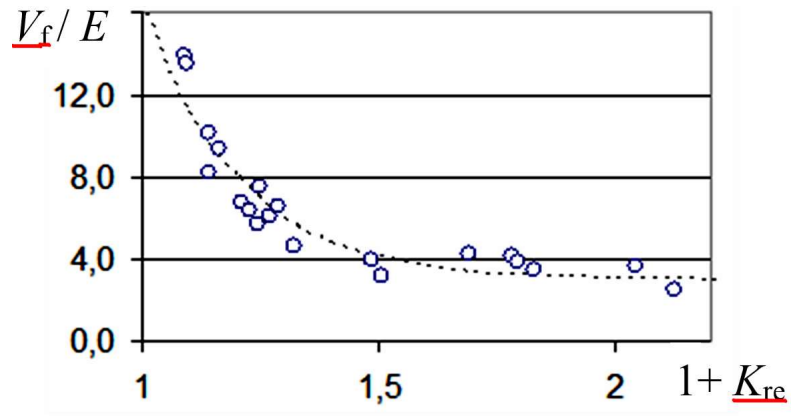

Fig. 4. Dependence of $\left(V_{\mathrm{f}} / E\right)$ on $\left(1+K_{\mathrm{re}}\right)$.

A sharp increase in the total recasting ratio during the transition to three-tiered excavation schemes leads to the decrease annual advance coal face line by 1.5-2 times compared 
to two-tiered excavation schemes to the complication of work organization and reduced effective capacity of dragline.

\section{Conclusion}

1. The dragline's excavation schemes at the combined mining system of the flat seam advisable to classify them according to the number of internal dump tiers (one-, two-, and three-tiered), which reflects the stripping cut volume with internal dump capacity.

2. The main technological indicators of dragline's excavation schemes, which determine their effectiveness, are the total recasting ratio and the annual advance coal face line.

3. For all models of dragline excavators, the dependence of the total recasting ratio on the non-transport bench height is not continuous.

A sharp increase in the total recasting ratio during the transition to three-tiered excavation schemes leads to the decrease annual advance coal face line by 1.5-2 times compared to two-tiered excavation schemes to the complication of work organization and reduced effective capacity of dragline.

If in the first case the jump of the recasting ratio is less than $5 \%$ of the overburden, then in the second case the recasting ratio more than doubled

4. As the non-transport bench height increases, when switching to three-tier excavation schemes, a sharp increase in the total recasting ratio causes a 1.5-2 times reduction in the rate of annual advance coal face line compared with two-tier excavation schemes.

\section{References}

1. H. Mirabediny, A dragline simulation model for strip mine design and development (University of Wollongong, Australia, 1998)

2. B. Erdem, N. Çelebi, A.G. Pasamehmetoglu, TIMNAQ, 107, A13 (1998)

3. W. Zhang, Q. Cai, S. Chen, IJMS, 6, 901 (2013)

4. J. Ma, Q.X. Cai, W. Zhou, S.Z. Chen, CNKI, 25:5, 662 (2006)

5. I.V. Nazarov, J. Min. Sci.,. 48:1, 55 (2011)

6. V.I. Cheskidov, V.K. Norri, J. Min. Sci., 52:4, 725 (2016)

7. V.I. Cheskidov, V.K. Norri, G.G. Sakantsev, J. Min. Sci., 50:4, 690 (2014)

8. S.G. Molotilov, V.I. Cheskidov, V.K. Norri, A.A. Botvinnik, J. Min. Sci., 45:1, 43 (2009)

9. S.G. Molotilov, V.K. Norri, V.I. Cheskidov, J. Min. Sci., 42:6, 622 (2006)

10. A.R. Mattis, V.I. Cheskidov, V.N. Labutin, J. Min. Sci., 48:2, 329 (2012)

11. B. Samanta, B. Sarkar, S.K. Mukherjee, Min. Techn., 111:2, 136 (2002)

12. A.V. Selyukov, J. Min. Sci., 51:5, 879 (2015)

13. A.V. Selyukov, Bulletin of the Tomsk Polytechnic University, Geo Assets Engineering, 326:12, 60 (2015)

14. A.V. Selyukov, Advanced technology based on new technological and organizational principles of spatial development of front of mining operations at open pits (Taishan Academic Forum - Project on Mine Disaster Prevention and Control, Taishan, 2014)

15. G.G. Sakantsev, V.I. Cheskidov, J. Min. Sci., 59:3, 501 (2014) 